\title{
SUCESIÓN DE UN NACIONAL BRITÁNICO RESIDENTE EN ESPAÑA: EL REENVÍO, DE NUEVO, COMO ELEMENTO DECISIVO ENTRE LA LIBERTAD DE TESTAR Y LOS DERECHOS SUCESORIOS DE LEGÍTIMA, TÍPICOS DEL DERECHO CIVIL COMÚN ESPAÑOL
}

\author{
SUCCESSION OF A BRITISH NATIONAL RESIDENT IN SPAIN: \\ RENVOI, AGAIN, AS A DECISIVE ELEMENT BETWEEN \\ FREEDOM TO MAKE A WILL AND THE LEGITIMATE \\ SUCCESSORY RIGHTS, TYPICAL OF THE SPANISH COMMON \\ CIVIL LAW
}

\author{
LAURA GARCÍA GuTIÉRREZ \\ Profesora Titular de Derecho Internacional Privado \\ Universidad Autónoma de Madrid
}

Recibido: 24.06.2019 / Aceptado: 22.07.2019

DOI: https://doi.org/10.20318/cdt.2019.4981

\begin{abstract}
Resumen: En este recurso de casación, resuelto por el Tribunal Supremo español, se plantea la admisibilidad del reenvío en la sucesión de un nacional británico que afecta a la propiedad de un inmueble situado en España. El Tribunal hace hincapié en su doctrina limitando el juego del reenvío cuando éste conduzca a la fragmentación de la sucesión. Al hilo de esta idea, analiza el concepto de domicilio en Derecho inglés y la incidencia de la fundación de un Trust conforme al Derecho de Malta en la sucesión del causante.

Palabras clave: ley aplicable a una sucesión mortis causa, libertad de testar, ley aplicable a la legítima, reenvío de retorno, Trust constituido conforme a un Derecho extranjero sobre bienes no situados en España.

Abstract: In this cassation appeal, resolved by the Spanish Supreme Court, the admissibility of the renvoi in the succession of a British national that affects the ownership of a property located in Spain is considered. The Court emphasizes its doctrine limiting the role of renvoi when it leads to the fragmentation of the succession. In line with this idea, it analyzes the concept of domicile in English Law and the incidence of the foundation of a Trust according to the Law of Malta in the succession of the deceased.

Keywords: law applicable to succession, Freedom to make a will, Law applicable to Spanish "legítima sucesoria", Renvoi, Trust founded according to a Foreign Law on goods located abroad.
\end{abstract}

Sumario: I. Introducción. II. Los hechos del supuesto resuelto en casación por el Tribunal Supremo en la Sentencia núm. 685/2018, de 5 de diciembre. III. El problema esencial que se aborda en este recurso: la incidencia del reenvío en la determinación de la ley aplicable a una sucesión anterior a la entrada en vigor del Reglamento 650/2012. IV. Otros problemas jurídicos interesantes tratados en esta decisión judicial: la noción de domicilio en el Derecho inglés. V. Resolución del supuesto si el fallecimiento del causante se hubiera producido en una fecha que hubiera permitido aplicar el Reglamento UE 650/2012, en materia de sucesiones. VI. Conclusiones. 


\section{Introducción}

1. De todos es sabido que, en el Derecho Internacional Privado español, con anterioridad a la aplicación del Reglamento de la Unión Europea ${ }^{1}$ en materia de sucesiones mortis causa ${ }^{2}$, la ley aplicable a una sucesión por causa de muerte se determinaba de conformidad con el art. 9.8 del Código Civil.

Este precepto legal contiene una norma de conflicto con un punto de conexión único basado en la nacionalidad del causante en el momento del fallecimiento. Se trata, por consiguiente, de un punto de conexión basado en la identidad cultural de la persona, que es lo que refleja la opción por la nacionalidad en este tipo de situaciones. En todo caso, si se opta por otorgar testamento, las disposiciones testamentarias, según el mismo art. 9.8, se rigen por la ley nacional del testador en el momento de su otorgamiento.

2. En este punto, el Derecho sustantivo español tiene una peculiaridad que se explicará más adelante en este comentario: el derecho de legítima. Se trata de una limitación a la libertad de disposición sobre el propio patrimonio en el momento del fallecimiento, por razón del parentesco.

Esta institución es objeto de discusión en la actualidad ${ }^{3}$ y es razonable que así lo sea, puesto que, en el fondo, el legislador está introduciendo un límite de disposición a los sujetos en cuanto al destino de sus bienes tras su fallecimiento. Parece que la libertad en este ámbito del Derecho Privado puede favorecer una mayor cooperación entre los miembros de las familias durante la vida de sus integrantes y, en todo caso, iría en la línea de favorecer la autonomía privada, el control sobre el patrimonio de cada sujeto.

En una concepción distinta, parece que al menos una parte importante del patrimonio personal sería colectivo, en el sentido de "común" a los miembros de la familia considerados herederos forzosos. En todo caso, no es el objeto del presente trabajo dar solución a esta compleja cuestión, que debería resolverse de acuerdo con los valores imperantes en la sociedad cuyas relaciones de Derecho Privado se trata de regular. De ahí, probablemente, las diferencias entre el Derecho sustantivo común español y el británico, a las que nos vamos a referir.

3. Este trabajo está, principalmente, orientado a analizar los problemas del supuesto desde la perspectiva del Derecho Internacional Privado. No obstante, es evidente que ello no puede realizarse sin tomar en consideración las consecuencias en el plano del Derecho sustantivo de lo afirmado aquí.

\section{Los hechos del supuesto resuelto en casación por el Tribunal Supremo en la Sentencia núm. 685/2018, de 5 de diciembre}

4. En este caso, el Tribunal Supremo resuelve un recurso de casación relativo a la sucesión de un nacional británico, D. Mateo, fallecido el 25 de julio de 2013 en Villalonga (Valencia), donde tenía su residencia habitual en el momento del fallecimiento.

El causante había otorgado testamento el 12 de diciembre de 2012, ante un notario de Gandía, en favor de su esposa, Dña. Bernarda, con la cual convivía cuando murió. En dicho testamento, D. Mateo instituía heredera a la demandada en relación con su patrimonio en España. Dicho patrimonio consistía en un inmueble destinado a la vivienda familiar de la pareja, situado en Villalonga. Asimismo, declaraba en este mismo documento, que su domicilio se encontraba en Reino Unido. Todo parece indicar que la pareja no tenía descendencia. No obstante, D. Mateo tenía dos hijos, que son quienes plantean la demanda.

Los hijos del fallecido, D. Francisco y D. Genaro, demandaron en instancia a Dña. Bernarda, reclamando, esencialmente, su declaración como herederos forzosos, legitimarios del causante. Esta declaración, de conformidad con el Derecho español ${ }^{4}$, implica que el causante no puede disponer li-

\footnotetext{
${ }^{1}$ En adelante, UE.

2 Reglamento 650/2012, de 4 de julio de 2012, relativo a la competencia, la ley aplicable, el reconocimiento y la ejecución de las resoluciones, a la aceptación y la ejecución de los documentos públicos en materia de sucesiones mortis causa y a la creación de un certificado sucesorio europeo, DOUE de 27 de julio de 2012.

${ }^{3}$ V. al respecto, por ejemplo, M. P. García Rubio/ T. F. Torres GARCía: La libertad de testar, Fundación Coloquio Jurídico, 2014.

4 Arts. 806 y 807 del Código Civil español.
} 
bremente de parte de su patrimonio al testar. Además, según su opinión, el domicilio del fallecido se encontraría en España, al haber vivido en este país de una manera estable y permanente desde 1998 y no en el Reino Unido, que es lo que declara el propio fallecido en el momento de designar como heredera del inmueble a la demandada.

5. Concretando más las peticiones de los demandantes, se debe destacar que reclamaron: en primer lugar, que se considerase nula la escritura de adjudicación de herencia de D. Mateo otorgada ante un notario de Gandía; en segundo término, que se redujese la institución como heredera de Dña. Bernarda, para respetar los derechos de legítima de los demandantes, y, por último, que se declarase que, como consecuencia de dicha calificación como legitimarios, les correspondería un sexto de lo recibido por Dña. Bernarda en propiedad y otro sexto en usufructo.

6. Por consiguiente, según su demanda, a la viuda le correspondería tan solo el usufructo del tercio de mejora y el tercio de libre disposición, que sería la única parte del patrimonio del causante sobre la que éste, según la opinión de los demandantes, podía disponer.

7. La parte demandada puso de manifiesto los demandantes habían recibido por otra vía bienes del causante. Según los datos que expone Dña. Bernarda, antes del deceso de D. Mateo, éste había constituido un Trust en Malta, por más de un millón de euros. Los beneficiarios de dicho Trust serían, precisamente los demandantes 5 . De tal manera que, de ser cierta dicha información, resulta evidente que los demandantes no se verían especialmente perjudicados si, dado el caso, se vieran desprovistos, en todo o en parte, de la propiedad del inmueble al que se refiere el litigio de la sentencia del Tribunal Supremo núm. 685/2018. De hecho, ya algún autor se ha referido expresamente al Trust como un instrumento de planificación sucesoria ${ }^{6}$.

8. Por otro lado, según la información facilitada por Dña. Bernarda, en el patrimonio del causante también se encontrarían activos financieros, tales como cuentas bancarias y acciones en Reino Unido, a los que tampoco parece referirse la escritura pública otorgada ante el notario de Gandía.

\section{El problema esencial resuelto en este recurso: la incidencia del reenvío en la determinación de la ley aplicable a una sucesión anterior a la entrada en vigor del Reglamento 650/2012}

9. En un supuesto como el descrito, la cuestión sobre cuál sea la Ley aplicable a la sucesión hereditaria se convierte en una decisión esencial ${ }^{7}$. De modo que conviene poner de relieve cómo la decisión en el escalón del Derecho Internacional Privado, previa a la resolución del problema sustantivo, no es en absoluto baladí, ni mucho menos superflua. Más bien al contrario, la decisión de política legislativa que implica el diseño de la norma de conflicto y la elección de su punto de conexión es, en la mayoría de las ocasiones, clave en relación con los intereses sustantivos de las partes y la satisfacción de sus derechos subjetivos.

\footnotetext{
${ }^{5}$ Es conocido que la figura del Trust es desconocida en el Derecho material español. Sin embargo, el Derecho Internacional Privado español se encuentra en ocasiones en la necesidad de solventar cuestiones relacionadas con ella, pues es típicamente empleada por los nacionales angloamericanos, dado que es un instrumento jurídico típico del Common Law. Como ya indicó hace tiempo M. Virgós Soriano, en su obra El Trust y el Derecho español, Madrid, Civitas, 2006, entre otras, p. 15 y 16: los bienes del Trust constituyen un fondo separado y no forman parte del patrimonio del trustee y quedan blindados de la herencia del fundador del Trust. Por su parte, los beneficiarios del Trust (en este caso, los demandantes) tienen sobre los bienes del Trust una suerte de "derecho real", con eficacia frente a terceros. Así, la separación de los fondos del Trust no entran en su herencia, ni se transmiten a sus herederos. Tampoco, en caso de insolvencia, pasarían a la masa de la quiebra, tampoco en el caso de la quiebra del trustee (p. 23). También puede consultarse, sobre la figura del Trust, el trabajo, algo menos reciente, de C. GonZÁLEz BeILfuss: La institución angloamericana del Trust y el Derecho Internacional Privado español, Barcelona, Bosch, 1997.

${ }^{6}$ V. M. VIRGÓs SORIANO: El Trust..., op.cit, p. 27.

${ }^{7}$ Lo cual recuerda, salvando las distancias por el tipo de materia e incluso por la cuantía, al tan acertado título del trabajo del profesor F. J. Garcimartín ALFérez "Cuando la norma de conflicto vale millones de dólares, el art. 9.2 del Directiva 98/26 y su desarrollo por el legislador español”, Revista de Derecho Comunitario Europeo, año núm. 3, núm. 6, 1999, pp. 419-428.
} 
En una controversia como esta, se trata, entonces, de decidir cuál es la Ley aplicable, tomando en consideración no solamente la norma de conflicto del Derecho Internacional Privado español, sino también el mecanismo del reenvío recogido en el art. 12.2 del Código Civil.

En este precepto legal, como es sabido, el Derecho autónomo español se muestra reacio a la admisión del reenvío, partiendo, en este sentido, de que toda remisión a un Derecho extranjero lo será, en principio, a su Derecho material ${ }^{8}$.

10. No obstante, en el Derecho Internacional Privado autónomo español, se contempla la posibilidad de tener en cuenta las normas de conflicto del Derecho extranjero cuando ello conduzca a una remisión al Derecho del foro. Es decir, que se rechaza el reenvío de segundo grado, pero se admite el reenvío de primer grado, también conocido como reenvío de retorno, por el efecto rebote al ordenamiento jurídico español provocado por los diferentes puntos de conexión de los ordenamientos jurídicos relevantes.

Parece evidente que, en el momento de la redacción del art. 12.2 del Código Civil, el legislador se mostró claramente partidario de favorecer la aplicación de su propia Ley frente al Derecho extranjero. Para ello, en todo caso, es necesario que la diferencia en los puntos de conexión del Derecho nacional y el Derecho extranjero permita esta segunda remisión ${ }^{9}$.

11. La técnica del reenvío, por lo tanto, puede modificar radicalmente la solución sustantiva de un litigio en el ámbito del Derecho privado, en la medida en que los puntos de conexión de los distintos ordenamientos jurídicos nacionales afectados responden a decisiones de política legislativa que reflejan opciones ideológicas diferentes, así como aspectos culturales y/o políticos y sociales propios de cada sociedad y de cada Estado.

En este caso, parece claro, dado que todos los tribunales involucrados parten de ello y ninguna de las partes lo discute, que la solución jurídica sustantiva varía en función de que el Derecho aplicable sea el español o el británico. La diferencia esencial radica en que en el Reino Unido se contempla la libertad de testar y, sin embargo, en el Derecho civil común español, como se ha explicado más arriba, prima la idea de que ciertos familiares se consideran herederos forzosos y se protegen sus expectativas en la sucesión mortis causa, a través de las legítimas ${ }^{10}$.

Por otro lado, también existen divergencias en el diseño de la norma de conflicto para localizar el ordenamiento jurídico aplicable en este tipo de situaciones sucesorias. Así, mientras en el Derecho Internacional Privado autónomo español, como he señalado, el punto de conexión para determinar la Ley aplicable es la nacionalidad del causante, en el Derecho inglés no se protege la unidad del patrimonio hereditario y se fragmenta la determinación de la Ley aplicable, dando relevancia a la noción de domicilio respecto de los bienes muebles y a la del lugar de situación respecto de los bienes inmuebles.

12. Históricamente, la idea de la unidad de la sucesión, propia del Derecho Internacional Privado español, en el que todo el patrimonio del fallecido se somete a un mismo ordenamiento jurídico, se ha concebido como un límite al reenvío de retorno. Así se ha puesto de manifiesto en algunas resoluciones del Tribunal Supremo citadas en esta misma sentencia 685/2018 ${ }^{11}$.

${ }^{8}$ V. al respecto, las explicaciones de S. Álvarez GonZÁlez: "El Reglamento 650/2012: disposiciones referentes a la sucesión de determinados bienes, reenvío y orden público", El Reglamento (UE) 650/2012: su impacto en las sucesiones transfronterizas, Colegio Notarial de Cataluña/ Marcial Pons, 2016, en especial, p. 138.

${ }^{9}$ Esta diferencia en los puntos de conexión escogidos por cada legislador es una decisión de política legislativa que muestra una diferente concepción jurídica del problema de que se trate en cada caso. Esta diferencia es, normalmente, reflejo de las preferencias sociales del momento o de los objetivos de política legislativa al que responda la ratio del sector de Derecho material de que se trate en cada caso.

${ }^{10}$ No obstante, es conveniente tener en cuenta que en el Derecho inglés existe una institución que cumple una función similar, las denominadas provisions (v, por ejemplo, las explicaciones de M. A. Cuevas de Aldasoro en "Título sucesorio de los ciudadanos británicos en España”, discurso leído el 14 de febrero de 2018 para acceder a la Real Academia de Legislación y Jurisprudencia de Murcia (accesible en internet), esp. p. 101.

${ }^{11}$ De todos es sabido que no es la primera vez que el Tribunal Supremo español se enfrenta a esta cuestión. A este respecto, son conocidas las sentencias de 15 de noviembre de 1996 y 21 de mayo de 1999 en las que el Tribunal Supremo se mostró partidario de aplicar la ley británica y negar el reenvío de retorno con el fin de respetar el principio de unidad y universalidad 
En el supuesto que estamos analizando, los demandantes defienden la aplicación del Derecho español precisamente apoyándose sobre la idea de que, si bien el causante era británico, los bienes del caudal hereditario se encuentran íntegramente situados en España. Por consiguiente, cabría tener en cuenta el reenvío en la medida en que conduce a la aplicación del Derecho español y que, además, al no haber bienes muebles que transmitir, no se produciría una fragmentación de la sucesión.

13. La demandada, por su parte, defiende que el sistema jurídico aplicable es el Derecho inglés, a resultas de la nacionalidad del causante y, por lo tanto, le ampara la libertad de testar propia de este ordenamiento jurídico. En cuanto a la posibilidad de reenvío, se encontraría entonces vedada por el hecho de que el domicilio del causante estaría en Reino Unido, como el mismo declara y se desprendería del arraigo que aún tendría con su localidad natal, y la fragmentación que supondría que, sin embargo, el inmueble objeto al que se refiere la controversia se encuentra en España.

Parece evidente que, en este punto, hay un salto argumentativo que se asume y que es preciso mencionar, desde la perspectiva del Derecho Internacional Privado: se está solucionando implícitamente el problema de aplicación relativo a la remisión a un sistema plurilegislativo ${ }^{12}$. Esta disposición establece, como es sabido, un sistema de remisión indirecta en el que se da preferencia a la solución prevista en el Derecho designado por la norma de conflicto española para solucionar el problema y determinar cuál es el Derecho definitivamente aplicable de todos aquellos que convivan en el sistema legal designado.

14. La demandada, como ya se ha mencionado, defiende que los demandantes ya han percibido, de algún modo, otros bienes del causante, puesto que en el patrimonio de D. Mateo también habría un Trust constituido en Malta. Según afirma el Tribunal Supremo al resolver el recurso, este dato se declara probado en la sentencia recurrida. Y, por otro lado, también existirían cuentas corrientes y algunos activos financieros localizados en Reino Unido.

15. El Juez de Primera Instancia entendió que el Derecho aplicable a esta sucesión sería el español, basando, de este modo, su respuesta en la pertinencia del reenvío de retorno, así como en la importancia de evitar el fraccionamiento de la sucesión. Desde su punto de vista, el domicilio del causante se situaría en España y también, en relación con los bienes inmuebles, el único existente estaría localizado en España.

Por consiguiente, para dicho Juez, el hecho de que el causante hubiera declarado en un documento público que su domicilio se encontraba en Reino Unido a efectos sucesorios no sería, en absoluto, determinante.

16. La Audiencia Provincial de Valencia (Sección $7^{\mathrm{a}}$ ), por el contrario, al resolver el recurso de apelación, se mostró partidaria de localizar el domicilio del demandado en Leeds (Reino Unido). Según se desprende también de la sentencia del Tribunal Supremo, los principales argumentos para afirmar esto serían: la propia declaración del fallecido al otorgar el testamento, que habría quedado acreditado cierto arraigo con su localidad natal y que allí conservaba algunas cuentas bancarias. Ello le condujo a estimar el recurso y desestimar la demanda, con lo cual se habría aplicado el Derecho inglés y descartado el reenvío. Esta resolución, desde luego, dejaba en mejor posición a la demandada que la de Primera Instancia.

Por su parte, el Tribunal Supremo establece, con claridad, en su sentencia, que la Ley aplicable a esta sucesión es el Derecho inglés, atendiendo a la nacionalidad del causante, de conformidad con lo establecido en el art. 9.8 del Código Civil. El Tribunal asume que existe la posibilidad teórica de un reenvío de retorno sobre la base de que los puntos de conexión del Derecho. No obstante, para determinar si una persona está domiciliada en Reino Unido, lo relevante es lo que establezca el Derecho británico a estos efectos y no tanto el concepto de domicilio en Derecho español. Esta afirmación la entronca el tribunal con la idea de la armonía internacional de soluciones, entendiendo que, cuando aplica el De-

\footnotetext{
de la herencia que recoge el art. 9.8 del Código Civil, mientras que en su sentencia de 23 de septiembre de 2002 optó por tener en cuenta el reenvío sobre la base de que el causante tenía a su fallecimiento solamente bienes inmuebles radicados en España (Muy bien explicado en el trabajo de M. A. Cuevas de Aldasoro antes citado, en esp. pp. 41 y 43).

${ }^{12}$ Este problema de aplicación, como es sabido, se regula en el art. 12.5 del Código Civil.
} 
recho extranjero, el juez español debe adoptar la posición más aproximada a cómo lo haría un Juez del Estado en cuestión ${ }^{13}$.

17. Parece lógico que, si estamos aplicando, o al menos teniendo en cuenta, lo dispuesto en una norma de conflicto de Reino Unido, debemos interpretar el punto de conexión de acuerdo con el Derecho de dicho Estado, pues forma parte de este sistema jurídico. Del mismo modo, cuando aplicamos una norma de conflicto de la lex fori, en este caso el Derecho español, el punto de conexión lo debemos interpretar de acuerdo con dicho ordenamiento jurídico. Por lo tanto, opino que tanto la Audiencia Provincial de Valencia, como el Tribunal Supremo, realizaron una interpretación adecuada del problema jurídico, cuando interpretaron el concepto de domicilio de conformidad con el Derecho inglés, y no con el art. 40 del Código Civil español, como pretendían los demandantes.

18. Por otro lado, en cierto modo, da la impresión de que el Tribunal busca una solución materialmente justa para el supuesto, en el que la esposa del fallecido quedaría en una posición muy desventajosa si ni tan siquiera pudiese heredar al fallecido en la titularidad de la vivienda habitual de ambos, teniendo en cuenta la cuantía del Trust. Pero esto no deja de ser una valoración personal, que no debe afectar a la búsqueda de la más correcta interpretación posible de las normas de Derecho Internacional Privado español en supuestos como este, tan frecuentes en la práctica de un Estado en el que conviven personas de diferentes nacionalidades, como es el nuestro.

\section{Otros problemas jurídicos interesantes tratados en esta decisión judicial: la noción de domici- lio en el Derecho inglés}

19. Un problema jurídico sobre el que también trata esta Sentencia del Tribunal Supremo es el concepto de domicilio en Derecho inglés. Es evidente que esta cuestión es un tema en sí mismo y que merecería una investigación independiente, debido, sobre todo, a las implicaciones que tiene como punto de conexión utilizado en diferentes sectores del Derecho. Concretamente, en Derecho de sucesiones y en la regulación de los impuestos. En el Common Law, la localización del domicilio puede resultar esencial para decidir, por ejemplo, si se aplica el Derecho del Reino Unido o bien un Derecho extranjero a un determinado problema jurídico ${ }^{14}$.

20. La importancia de la localización del domicilio, en este caso, afecta directamente a la admisibilidad o no del reenvío, dado que el bien situado en España (el inmueble) no puede ser incluido en el Trust $t^{15}$ y quedaría sometido al Derecho español, por ser el del lugar de situación, según el Derecho Internacional Privado inglés. La posible fragmentación de la sucesión, como ya se ha señalado, puede fundamentar la exclusión el reenvío de retorno en nuestro sistema, que se apoya en la idea de la unidad de la sucesión. De ahí que la situación del domicilio del causante en Reino Unido o en España sea determinante en esta litis. Y, por ello, además, se entiende que se aporte en el procedimiento un Informe sobre esta noción, que no coincide con la equivalencia domicilio - residencia habitual propia del Derecho Privado español, a raíz de lo dispuesto en el art. 40 del Código Civil y de la jurisprudencia del Tribunal Supremo interpretándolo a la que el propio Tribunal hace referencia en la última parte del Fundamento Jurídico Tercero.

No existe en Derecho inglés una definición legal expresa ${ }^{16}$ del concepto de "domicile”, pero sí que es determinante, como ocurre en la controversia que estamos analizando, la elección por parte de aquellas personas que se trasladan a trabajar o a residir a otro país. El mero hecho de trasladarse a otro

${ }^{13}$ La frase del Tribunal Supremo es contundente: “...Es asi porque siempre que debe aplicarse un Derecho extranjero por el juez español, éste debe fallar del modo más aproximado a como lo haría un tribunal de dicho Estado y ha de aplicar el Derecho extranjero en su integridad".

${ }^{14}$ Muy bien explicado en https://www.russell-cooke.co.uk. Página consultada el 23 de junio de 2019.

${ }^{15}$ Sobre la necesaria exclusión al constituir o reconocer un Trust de los bienes situados en España, v. la precitada obra de M. Virgós Soriano: El Trust y..., op. cit, p. 38.

${ }^{16} \mathrm{~V}$. las explicaciones contenidas en la página web citada más arriba. 
estado con cierto ánimo de estabilidad no sería suficiente para afirmar un cambio de domicilio, si no se comprueba dicha intencionalidad por parte de la persona afectada. De ahí la importancia de las manifestaciones de D. Mateo en la escritura pública otorgada en Gandía, así como de otros factores, como la existencia de ciertos vínculos, tanto personales como patrimoniales, con su país de origen.

Además, el domicilio se refiere a una nación en concreto: en este caso a Inglaterra, en lugar de a Reino Unido como Estado en su conjunto.

21. Estos datos parecen indicar, por consiguiente, que la decisión de la Audiencia Provincial y del Tribunal Supremo, primando la voluntad del causante en relación con su domicilio a efectos sucesorios, es acertada. Por lo que, en cuanto a los bienes muebles, el Derecho aplicable no sería el Derecho español, sino el Derecho inglés, y ello impediría el juego del reenvío.

\section{Resolución del supuesto si el fallecimiento del causante se hubiera producido en una fecha que hubiera permitido aplicar el Reglamento UE 650/2012, en materia de sucesiones}

22. A la hora de resolver este supuesto, la fecha del fallecimiento de D. Mateo tiene una importancia fundamental, del mismo modo que la fecha de las disposiciones mortis causa a las que se refiere la sentencia. La razón para afirmar esto, como ya se ha señalado más arriba, es que el Reglamento UE 650/2012, que regula los diversos aspectos de las sucesiones mortis causa que afectan al Derecho Internacional Privado $^{17}$, se empezó aplicar a las personas fallecidas a partir del 17 de agosto de 2015, aunque, como establece su art. 83, puede aplicarse a algunas disposiciones mortis causa elaboradas antes de esa fecha.

En el caso que estamos analizando, la aplicación del Reglamento afectaría claramente a la solución del asunto. El Reglamento parte, con carácter general, de un criterio de conexión diferente: la residencia habitual del causante en el momento del fallecimiento ${ }^{18}$. En definitiva, se opta por el centro de intereses vitales del fallecido, por el Estado en el que principalmente habita. Existe, no obstante, la posibilidad de elegir la ley aplicable con ciertos límites ${ }^{19}$.

23. Por lo tanto, en principio, la Ley aplicable a este problema sucesorio, salvo que entendamos que de lo manifestado por el causante en la escritura pública se deduce una elección tácita del Derecho inglés, sería el Derecho español, sin posibilidad de reenvío, como es lógico.

También la regulación del reenvío es bastante diferente a la del Derecho autónomo español en este Reglamento $\mathrm{UE}^{20}$. Parece descartarse el reenvío de retorno, pues el art. 34 del reglamento no hace referencia alguna al mismo. A mi entender, este precepto tan solo está admitiendo el reenvío cuando la remisión inicial de la norma de conflicto nos conduce a la aplicación del Derecho de un tercer Estado. El silencio respecto de otras posibilidades, creo que las está excluyendo. No las regula, porque no las admite. Eso implicaría que, en un supuesto como el que nos ocupa, si pudiéramos llegar a concluir que hay una elección tácita del Derecho inglés, ello impediría el juego del reenvío por no tratarse del ordenamiento jurídico de un tercer Estado.

24. En los casos en que la norma de conflicto sí efectúa una remisión inicial al Derecho de un tercer Estado, sí se admite el reenvío, siempre que las normas de conflicto de dicho Estado utilicen un punto de conexión diferente y que remitan: bien a la Ley de un Estado miembro de la UE o bien a la Ley de un tercer Estado que no remite a un ordenamiento jurídico diferente.

25. Se trata, por lo tanto, de limitar el reenvío a los casos en los que la remisión inicial conduzca a Ley de un Estado no miembro, siempre que se produzca el retorno al Derecho de un Estado miembro

${ }^{17}$ En relación con este Reglamento, v. A. Bonomi/ P. WAUtelet: El Derecho europeo de sucesiones, Cizur Menor, Aranzadi, 2015.

${ }^{18} \mathrm{~V}$. art. 21 del Reglamento y 25 en cuanto a los pactos sucesorios.

${ }^{19}$ V. esencialmente, el art. 22 del Reglamento.

${ }^{20}$ V. art. 34 del Reglamento. 
o bien que se produzca la remisión al Derecho de un tercer Estado que no contenga remisión alguna a otro ordenamiento jurídico. miembros.

Se potencia claramente así la aplicación, sobre todo, del Derecho de sucesiones de los Estados

\section{Conclusiones}

26. En la sentencia del Tribunal Supremo núm. $685 / 2018$ se resuelve un litigio en materia de sucesiones mortis causa aún no regido por el reglamento UE 650/2012, sino por el Derecho Internacional Privado autónomo español. Al aplicarse el art. 9. 8 del Código Civil para determinar la Ley aplicable a la sucesión, prima el criterio de la nacionalidad del causante. No obstante, se discute la admisibilidad del reenvío, siempre condicionada en nuestro sistema por la idea de la unidad y la universalidad de la sucesión.

A la hora de decidir sobre la admisibilidad del reenvío, es fundamental el concepto de domicilio previsto en el Derecho inglés, que, en este caso, parece estar localizado en Reino Unido, según declaró el propio fallecido en le escritura en la que nombraba a su esposa heredera del inmueble situado en España objeto de controversia. Ello conduciría, como acertadamente establecen tanto la Audiencia Provincial de Valencia como el Tribunal Supremo a impedir el juego del reenvío para no poner en riesgo la unidad de la sucesión.

27. Todo apunta, sin embargo, a que, de haber sido aplicable a este supuesto el Reglamento 650/2012 la solución al mismo hubiera variado, puesto que han cambiado tanto el punto de conexión generalmente aplicable, como la regulación del reenvío, si comparamos con el Derecho autónomo español.

28. En mi opinión, el cambio de criterio del legislador de la UE en favor de la residencia habitual es positivo, en la medida en que no priva a las personas de la posibilidad de someter su sucesión a la Ley de su nacionalidad, si ese es su deseo.

Más compleja parece la regulación del reenvío en este nuevo instrumento de la UE, por lo que parece preciso un estudio en profundidad de las consecuencias prácticas de esta nueva regulación.

En todo caso, la aproximación que hace al supuesto el Tribunal Supremo me parece bastante adecuada, dentro de la brevedad con la que se acerca a estas cuestiones que presentan una cierta complejidad y en las que se plantea claramente un juego de suma cero entre las partes. 